African porcupine quill both correspond to strong reflexions in feather rachis and may have the same origin. (c) Astbury ${ }^{13}$ and MacArthur ${ }^{2}$ have shown that reflexions from frog muscle at approximate multiples of $1.50 \mathrm{~A}$. are due in part to collagen and in part to actin. Bear's clam muscle (type II) gives reflexions similar to those of frog muscle which may be accounted for in the same way ${ }^{14}$. In clam muscle (type I) Bear does not list any meridional reflexions below 18.2 A. (apart from the 5.1-A. reflexion) ${ }^{15}$. When such high multiples of $1.50 \mathrm{~A}$. are considered, spacings would have to be known with great accuracy before a correlation could be definitely established.

Feather rachis keratin. I agree with Pauling and Corey that the absence of the 1/5-A. reflexion does not necessarily exclude the presence of $3 \cdot 7$-residue helices. Their remarks have led me to re-examine the X-ray diffraction pattern of feather rachis. Oscillation photographs taken about the normal to the fibre axis indicate that the strong reflexion at $3.07 \mathrm{~A}$. has a structure factor which is about twice as large as that of any other meridional or near-meridional reflexion. The reflexion at $5 \cdot 53$ A., quoted by Pauling and Corey in support of the presence of $3 \cdot 7$-residue helices, is weak and consists of two separate reflexions the normals of which make an angle of about $22^{\circ}$ with the meridian. There is no reflexion at $0.75 \mathrm{~A}$., such as would be expected on the basis of the structure proposed by Pauling and Corey ${ }^{1}$. These results suggest that the correct solution may be of the type originally proposed by Astbury and Woods, with chains of the $\beta$-type playing a dominant part in the crystalline fraction of the fibre ${ }^{16}$.

M. F. Perutz

Medical Research Council Unit for the Study of the Molecular Structure of Biological Systems, Cavendish Laboratory, Cambridge.

${ }^{1}$ Pauling, I.., and Corey, R. B., Nature, 168, 550 (1951),

${ }^{2}$ Perutz, M. F., Nature, 167, 1053 (1951).

${ }^{3}$ Pauling, L., Corey, R. B., and Branson, H. R., Proc. U.S. Nat. Acad. Sci., 37, 205 (195i).

4 Bragg, W. I., Kendrew, J. C., and Perutz, M. F., Proc. Roy. Soc., A, 203, 321 (1951).

"Astbury, W. Tr, reported at the Int. Congress of Crystallography, Stockholm, July 2,1951 .

- Brown, L. (private communication).

${ }^{2}$ MacArthur, I., Nature, 152, 38 (1943).

A Ambrose, E. J., and Elliott, A., Proc. Roy. Soc., A, 208, 206 (1951).

- Astbury, W. T., J. Chem. Soc., 337 (1942)

${ }^{10}$ Ambrose, E. J., and Elliott, A., Proc. Roy. Soc., A, 205, 47 (1951).

Patlling, L., and Corey, R. B., Proc. U.S. Nat. Acad. Sci., 37, 267 (195i).

${ }^{12}$ Bailey, K., Astbury, W. T., and Rudall, K. M., Nature, 151, 716

${ }^{13}$ Astbury, W. T., Nature, 160, 388 (1947).

${ }^{14}$ Bear, R. S., J. Amer. Chem. Soc., 67, 1625 (1945)

is Bear, R. S, J. Amer. Chem. Soc., 66, 2043 (1944).

${ }^{16}$ Astbury, W. T., and Woods, H. J., J. Text. Inst., 23, 17T (1932).

\section{Action of Terramycin and Chloromycetin on Cholera Vibrio in Mice}

TERRAMYcin hyDRochloride (Pfizer) was tested in mice inoculated with Vibrio cholera. The animals were inoculated intraperitoneally with a suspension of $1 \mathrm{ml}$. of an 18-hr. old culture; the suspension contained $50 \times 10^{6}$ organisms per ml. and 5 per cent mucin (Armour) ${ }^{1}$. These inoculations were fatal in $48 \mathrm{hr}$. Four strains (Ogawa 41, Inaba 35 and 29, and a Mediterranean Inaba strain) were employed.

In the first series of experiments, in which the antibiotic was administered intraperitoneally in single graduated doses half an hour after the infection, 15 out of 15 animals, infected with the Inaba strains, recovered after treatment with $5-10 \mathrm{mgm} . / \mathrm{kgm}$. of terramycin. The strain Ogawa 41 was more resistant and required $15 \mathrm{mgm} . / \mathrm{kgm}$. in order to produce a 100 per cent survival.

Larger doses of antibiotic were required to control the infection when administered five hours after inoculation: $15 \mathrm{mgm} . / \mathrm{kgm}$. in the case of the Inaba 35 strain, $30 \mathrm{mgm}$. $\mathrm{kgm}$. for the Inaba 29, the Mediterranean Inaba, and the Ogawa 41 strains. With these quantities, all 15 animals of the series survived.

A period of five hours seems to be the limit of time after infection in which the terramycin is effective. In experiments with the Inaba 35 strain, even 300 $\mathrm{mgm} . / \mathrm{kgm}$. was ineffective after seven hours from the time of infection.

If administered half an hour after the infection, chloromycetin (Parke, Davis and Co.) was curative in doses of $25 \mathrm{mgm} . / \mathrm{kgm}$. in the case of Inaba 35 , of $50 \mathrm{mgm} . / \mathrm{kgm}$. in the case of the other two Inaba strains, and of $100 \mathrm{mgm} . / \mathrm{kgm}$. in Ogawa 4l. These results are in agreement with those reported by Gauld et $a l .^{2}$.

Five hours after the infection, $250 \mathrm{mgm} . / \mathrm{kgm}$. of chloromycetin was still effective in the case of the Inaba 29 and the Mediterranean Inaba strains (20 mice; 100 per cent survival), but was only partially effective against the Ogawa 41 and Inaba 35 strains (10 mice; 30 per cent survival).

\section{E. OLEJNIK \\ S. Davidovitch}

Microbiological Laboratories,

Weizmann Institute of Science, Rehovoth, Israel. May 20.

${ }^{1}$ Griffits, Y. Y., Public Health Reports, 57, 707 (1942). ${ }^{2}$ Gauld, R. L., Schlingman, A. S., Jackson, E. B., Manning, M. C.,

\section{Caulobacter versus Bacillus spec. div.}

THE study of sessile freshwater bacteria induced Henrici and Johnson ${ }^{1}$ to draw up a preliminary taxonomic system comprising many sessile species. They brought all these together in one order, Caulobacteriales; Caulobacter being the name given to one of the genera. This genus is characterized by the presence of a stalk connecting one end of the elongated bacterial body to a solid substrate and by multiplication by transverse binary fission. 'The first to describe such a bacterium, without giving it a name, was Jones ${ }^{2}$.

Some strains, probably all to be classified as one species of this genus, have been isolated at Delft from tap water. The development of Caulobacter can be promoted by adding peptone water to the tap water so as to make a 0.01 per cent solution. The bacterium will then be found at the lower end of its stalk hanging down from the surface of the water. If a thin collodion film, such as is used as a specimen carrier in the electron microscope, is made to float on the surface, the bacterium attaches itself to the film. To obtain a preparation suitable for the electron microscope, one merely has to lift the film with a specimen carrier and to rinse it with distilled water ${ }^{3}$.

Isolated in pure culture, Caulobacter may be cultivated on 1 per cent peptone agar; but single colonies always remain very small. In 1 per cent peptone water the bacteria produce irregular long forms ; in $0 \cdot 1$ per cent peptone water more-normal single 